\title{
The occurrence of fire influences the tree stratum of the Tabebuia aurea monodominant stands "Paratudal" in the Pantanal of Miranda/MS?
}

\author{
Daniel Manrique Pineda ${ }^{1 *}$, Geraldo Damasceno Junior ${ }^{l}$
}

\begin{abstract}
${ }^{1}$ Laboratório de Ecologia Vegetal, Instituto de Biologia, Fundação Universidade Federal de Mato Grosso do Sul (UFMS), Ibama), Campo Grande, Brasil

${ }^{*}$ Contact E-mail: dampmen201@gmail.com
\end{abstract}

\begin{abstract}
The Pantanal is located in the center of the South American continent, mainly in Brazil. The geomorphological complexity and waters of the rivers that descend to the Pantanal generate a seasonal flood cycle,that influences the organization of different landscapes with their phytophysiognomies and distribution of species. In these landscapes there are many types of monodominant stands, that are associated with diverse flood levels. The formation of Tabebuia aurea (Bignoniaceae) locally known as "Paratudal" is commonly associated with areas of higher flood, influence and occur in fire prone areas. Besides, this species is used by local communities as medicinal and source of wood. This study aims to analyze the impact of fire under different frequencies, in the tree community of $T$. aurea. Thirty-nine areas with fire frequencies between 2 to 9 years from 2003 to 2017, were selected through heat spots information and Landsat satellite images. We sampled all tree individuals with circumference at breast height equal or greater than $10 \mathrm{~cm}$ in four $25 \times 25 \mathrm{~m}$ per area. We also measured the height of the watermark left by the last flooding in each tree. Preliminary GLM tests showed decreasing abundance and species richness in areas with higher fire frequency and higher flood levels, compared to lower fire frequency and lower inundation. We conclude that this interaction of fire and flood is probably related to the monodominance of $T$. aurea.
\end{abstract}

Keywords: Pantanal, phytophysiognomies, fire frequency, satellite images, environmental filters 